\title{
Development and validation of the patient-rated ulnar nerve evaluation
}

\author{
Joy C MacDermid ${ }^{1,2^{*}}$ and Ruby Grewal ${ }^{1}$
}

\begin{abstract}
Background: Compression neuropathy at the elbow causes substantial pain and disability. Clinical research on this disorder is hampered by the lack of a specific outcome measure for this problem. A patient-reported outcome measure, The Patient-Rated Ulnar Nerve Evaluation (PRUNE) was developed to assess pain, symptoms and functional disability in patients with ulnar nerve compression at the elbow.
\end{abstract}

Methods: An iterative process was used to develop and test items. Content validity was addressed using patient/ expert interviews and review; linking of the scale items to International Classification of Functioning, Disability, and Health (ICF) codes; and cognitive coding of the items. Psychometric analysis of data collected from 89 patients was evaluated. Patients completed a longer version of the PRUNE at baseline. Item reduction was performed using statistical analyses and patient input to obtain the final 20 item version. Score distribution, reliability, exploratory factor analysis, correlational construct validity, discriminative known group construct validity, and responsiveness to change were evaluated.

Results: Content analysis indicated items were aligned with subscale concepts of pain and sensory/motor symptoms impairments; specific upper extremity-related tasks; and that the usual function subscale provided a broad view of self-care, household tasks, major life areas and recreation/ leisure. Four subscales were demonstrated by factor analysis (pain, sensory/motor symptoms impairments, specific activity limitations, and usual activity/role restrictions). The PRUNE and its subscales had high reliability coefficients (ICCs > 0.90; 0.98 for total score) and low absolute error. The minimal detectable change was 7.1 points. It was able to discriminate between clinically meaningful subgroups determined by an independent evaluation assessing work status, residual symptoms, motor recovery, sensory recovery and global improvement) $p<0.01$. Responsiveness was excellent (SRM $=1.55$ ).

Conclusion: The PRUNE is a brief, open-access, patient-reported outcome measure for patients with ulnar nerve compression that demonstrates strong measurement properties.

\section{Background}

Compression of the ulnar nerve at the elbow (UNE), sometimes referred to as cubital tunnel syndrome, is the second most common compression upper extremity neuropathy [1]. The mean annual incidence has been estimated at 25 cases per 100,000 person-years, with the male to female difference being 33 to 17 . Work-relatedness has been suggested; since males performing manual work have an elevated incidence of 57 cases/100,000 person-years [2]. A number of studies have related development of symptoms to occupational activities including sustainable flexion postures [3,4] and repetitive elbow movement; or sporting

\footnotetext{
* Correspondence: jmacderm@uwo.ca

'Hand and Upper Limb Centre, 268 Grosvenor St, London, Ontario N6A 3A8, Canada

${ }^{2}$ School of Rehabilitation Science, McMaster University, Hamilton, Ontario L8S

1C7, Canada
}

activities like cycling [5]. The prevalence of UNE is 3.5 times higher in people who report occupational activities that involve 'holding a tool in position' [4] compared to workers in the same setting who do not perform this task. However, other physical and psychosocial factors can also contribute to UNE [6]. In a multidimensional risk study, smoking, education level and work experience were identified as risk factors; whereas, gender, BMI, alcohol consumption, trauma to the elbow, diabetes mellitus, and hypertension were not [7].

Evidence on the management of UNE is problematic; and indicates a need for better outcome reporting. A Cochrane review was only able to locate six low-quality clinical trials relating to management of ulnar neuropathy. This review concluded " available evidence is not sufficient to identify the best treatment for idiopathic ulnar neuropathy 
at the elbow on the basis of clinical, neurophysiological and imaging characteristics. We do not know when to treat a patient conservatively or surgically." [8] This review recommended that future research would be improved by the use of validated disease-specific clinical outcome measures. Our systematic review of prognosis following anterior ulnar nerve transposition faced similar challenges [9]. Although, we were able to locate 26 studies addressing prognosis following ulnar nerve transposition surgery, only two of these were high-quality. We found profound inconsistencies in the design and conclusions of available studies; and were unable to make any conclusions based on the studies located. We found the lack of standardized evaluation of outcomes was a substantial barrier to the conduct of an effective systematic review.

Although the evidence about treatment and prognosis has flaws, it is clear that ulnar nerve compromise can lead to substantial disability. In a qualitative study of patients with ulnar nerve palsy, the majority of people had difficulties with simple, everyday tasks including holding soap,eating, buttoning clothes, holding a glass or lifting small objects [10]. Ulnar nerve compression causes less compromise to the ulnar nerve, but also results in substantial hand impairments [11]. Despite the unique and potentially profound consequences of ulnar nerve problems, there has been little attention to developing and validating UNE disease-specific patient report outcome measures. A systematic review of the outcomes measures used to assess outcomes of UNE identified 42 clinical studies [12] that used 21 different health outcomes measures including 2 generic instruments; 10 nonstandardized measures; 3 symptom-specific patient-reported instruments; and 6 patient questionnaires. A review of standardized rating systems for evaluation of the elbow did not locate any tools specific for UNE [13]. Further, this review noted that most scoring systems used to evaluate elbow function have limited supporting psychometric data.

In 2006, Mondelli and colleagues described a 9-item UNE scale developed in Italian and then translated to English [14]. It was developed in Italian, and published with an English translation. Data from this questionnaire were compared to nerve physiological features, clinical measures and the Boston Carpal Tunnel Questionnaire [15]. The scale had low correlation to electrophysiology grade, and moderate correlation to clinical severity. Test-retest reliability in the first 44 patients was excellent (0.97) and responsiveness was acceptable in 25 patients followed 6-8 months of conservative management (effect size $=0.46$ ). The item development $/$ reduction process and translation process were not reported. It has not been widely used in subsequent research.

The purposes of this paper are to report the development and validation of a patient-report outcome measure that is designed for use in patients with ulnar nerve compression. Specific objectives include to describe the development process, reliability, content and construct validity, and factor/structural validity.

\section{Methods}

The Patient-Rated Ulnar Nerve Evaluation (PRUNE) was developed based on iterative revisions and stakeholder consultation. A formal structured examination of content validity; a statistical analysis of test-retest reliability, factor structure, and construct validity were used for item reduction and evaluation of the final instrument.

\section{Scale development process}

The first author has developed previous PRO that have a common structure of pain, specific activity and usual activity subscales [16-19] disorders. This structure informed the structure of the PRUNE. The specific items were developed through patient interviews, epidemiological and biomechanical studies. Symptoms that were relevant to patients with ulnar nerve compression neuropathy were grouped into: pain and ulnar-nerve "specific" sensory symptoms or motor symptoms. Together with the specific activities and usual functional activities, 4 subscales were derived. A long version of the instrument was completed by all participants and the final reduced scale was determined by a structured item reduction process. Cross correlations between items, factor analysis, inspection for floor and ceiling effects and item distribution were used to reduce the item pool to the optimal set of items.

\section{The patient-rated ulnar nerve evaluation (PRUNE)}

The final version of the PRUNE is presented in Figure 1. The PRUNE is a 20-item scale that measures pain, sensory/motor symptoms and functional disability in patients with UNE. The 20 items include: 6 pain, 4 sensory/ motor symptoms 6 specific activity; and 4 usual activity (personal care, household, work and recreation) items. Each item is scored on a scale from zero (none/no difficulty) to 10 (worst possible/completely unable). Each subscale is scored by adding the component questions (pain/60, sensory/motor symptoms/40, specific activity/ 60 , usual activity/40). The total score is calculated to range from 0-100 points with zero meaning no symptoms or difficulty and 100 being worst possible symptoms and completely unable to do all functional activity. The total score equally weights the 10 items on symptoms and 10 functional items (by dividing the grand total by 2 ).

The individual items retained during item reduction are in the appended instrument (Figure 1) which is the final format for the PRUNE. Items modified in the final stage of beta testing and the rationale is listed in Table 1 to document the rationale for item reduction. 


\section{PATIENT RATED ULNAR NERVE EVALUATION}

Name:

Date:

The questions below will help us to understand the amount of pain or difficulty you experience because of your hand/arm. Please describe your average experience over the past week.

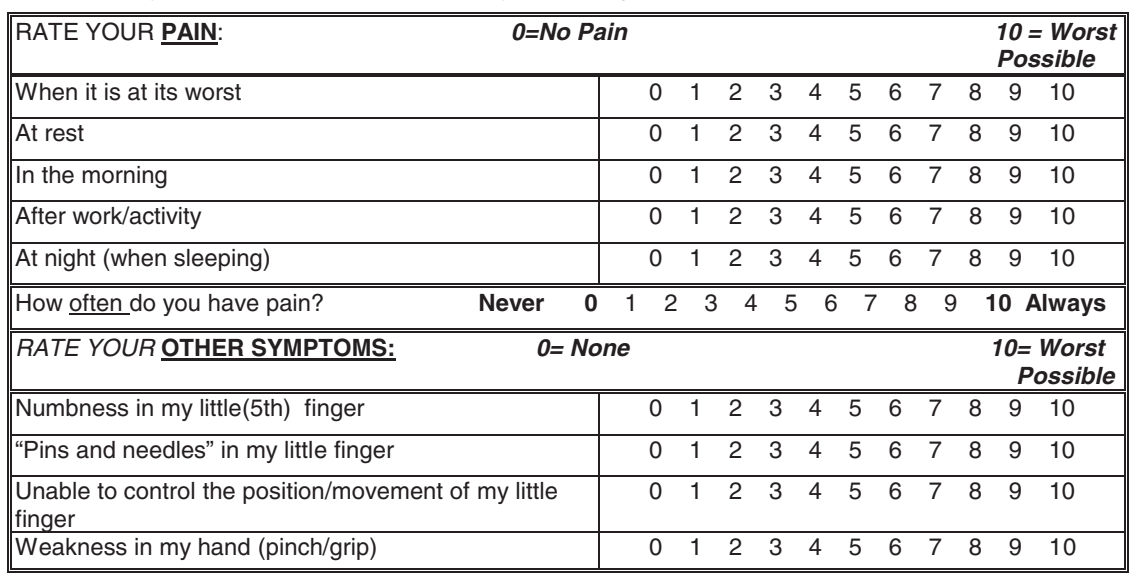

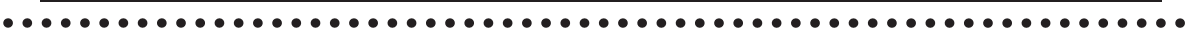

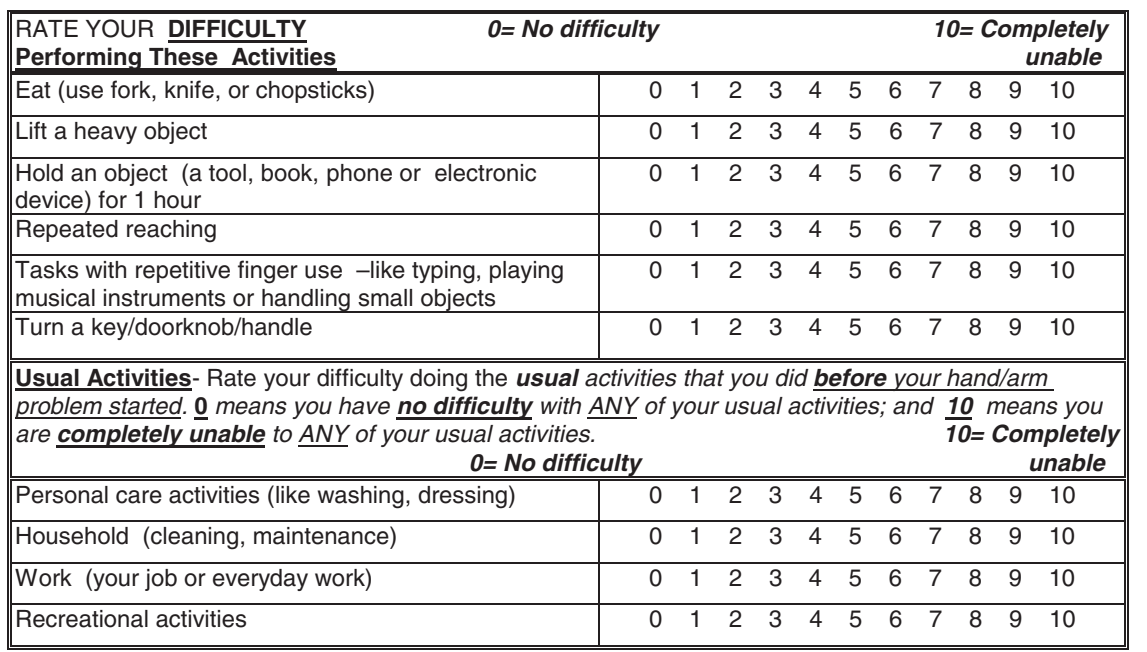

Figure 1 Patient-rated ulnar nerve evaluation.

\section{Treatment}

This study was not designed to study intervention effects. However, response to treatment was used as a context to evaluate the clinical measurement property of responsiveness. Patients underwent a submuscular or subcutaneous ulnar nerve transposition using established procedures [20-22].

\section{Comparison study measures}

\section{The SF-36}

The SF-36 is a 36-item scale that addresses general health. Subscales address Physical Function, Physical Role, Bodily Pain, General Health, Vitality, Social Function Emotional Role, and Mental Health. These subscales are summarized into Physical and Mental Summary Component scores. While the SF-36 is less responsive than disease-specific scales [23,24], it is a valid indicator of general health status in musculoskeletal disorders [25]. General health status measures are commonly used in construct validation and are expected to have a low to moderate relationship with a disease-specific measure like the PRUNE.

\section{The bishop scale}

The Bishop Scale (sometimes referred to as Kleinman and Bishop) [26] is a clinician administered measure developed specifically for UNE. The scale addresses: satisfaction, improvement, severity of symptoms, work status, leisure activity, strength, and sensibility. There is no description of standardized application of the tool; nor has reliability, validity or responsiveness been reported [12]. The Bishop scale was administered by an independent evaluator and the items were used for criteria to test known group validity since the scale provides criteria for a number of clinically relevant subgroups. 
Table 1 Patient demographics

\begin{tabular}{|c|c|}
\hline Characteristic $(n=89)$ & Descriptors \\
\hline \multirow[t]{2}{*}{ Age in years } & Range $20-81$ \\
\hline & Mean $=52.75 ;$ SD- 12.86 \\
\hline Gender & $\%$ \\
\hline Male & 75 \\
\hline Female & 25 \\
\hline Workers compensation status & $\%$ \\
\hline No & $82 \%$ \\
\hline Yes & $15 \%$ \\
\hline Claim in progress & $3 \%$ \\
\hline Type of work & $\%$ \\
\hline Heavy repetitive & 37 \\
\hline Heavy intermittent & 18 \\
\hline Light repetitive & 18 \\
\hline Light intermittent & 28 \\
\hline Work status & $\%$ \\
\hline Normal duties & 21 \\
\hline Light duties at same work place & 15 \\
\hline Off work due to arm & 18 \\
\hline Handedness & $\%$ \\
\hline Left & 7 \\
\hline Right & 93 \\
\hline Surgical side & $\%$ \\
\hline Left & 58 \\
\hline Right & 43 \\
\hline Electrodiagnostic findings & $37.47 \mathrm{~m} / \mathrm{s}$ \\
\hline AE-MNCV & $50.65 \mathrm{~m} / \mathrm{s}$ \\
\hline BE-MNCV & $13.17 \mathrm{~m} / \mathrm{s}$ \\
\hline $\mathrm{DNCV}(\mathrm{m} / \mathrm{s})$ & $3.79 \mathrm{mV}$ \\
\hline AE-CMAP & $17.29 \%$ \\
\hline BE-CMAP & $4.98 \mathrm{mV}$ \\
\hline CMAP ADQ amplitude & $5.74 \mu \mathrm{V}$ \\
\hline SNAP digit V & $21.42 \mathrm{~ms}$ \\
\hline SNCV digit V (ms) & $75 \%$ \\
\hline Surface EMG confirmed & $89 \%$ \\
\hline \multicolumn{2}{|l|}{ Needle EMG confirmed } \\
\hline McGowan stage [1] & $\%$ \\
\hline 0 & 0 \\
\hline । & 13 \\
\hline$\|$ & 46.4 \\
\hline III & 40.6 \\
\hline
\end{tabular}

CMAP, Compound motor action potential. SNAP, sensory nerve action potential. MNCV, Motor nerve conduction velocity. AE-CMAP CMAP from above elbow to below elbow. AE-MNCV MNCV from above elbow to below elbow. BE-CMAP CMAP from below elbow to wrist.

BE-MNCV MNCV from below elbow to wrist. Reference List [1] McGowan AJ: The Results of Transposition of the Ulnar Nerve for Traumatic Ulnar Neuritis. J Bone Joint Surg 1950, 32: 293-301.

\section{Patient recruitment}

Patients $(\mathrm{n}=89)$ were diagnosed in a multi-stage process. The preliminary diagnosis was made by the family physician who then referred the patient for electrodiagnosis and examination by a physical medicine physician. The electrodiagnostic parameters as reported in patient demographics and clinical presentation were considered to make the definitive diagnosis. Patient with a confirmed ulnar neuropathy were sent to surgical consultation with a fellowship trained hand surgeon, who again confirmed the diagnosis again using electrodiagnostic findings and clinical examination. Patients undergoing anterior nerve transposition were approached and agreed to participate in this study. Inclusion criteria included electrodiagnostically confirmed ulnar nerve compression at the elbow, persistent symptoms for at least 3 months with failed conservative management, and able to return for follow-up. Exclusion criteria included: unable to complete self-report forms, central or spinal neurological disorders, other neuropathy affecting the hand (excluded by electrodiagnosis) and medical conditions that precluded participation. Respondents completed the full version of the PRUNE within 2 weeks prior to surgery; and again 3 and 24 months following surgery.

The study was approved by the Western University Ethics Board. Written informed consent for participation in the study was obtained from all participants; none were under 18 years of age.

\section{Analyses}

\section{Scale distributions and floor/ceiling}

Box plots were used to examine the distribution of scores for individual items and subscales to examine potential floor/ceiling effects or distribution problems.

\section{Content validity}

Content validity is fundamental to scale validity and was assessed by four methods. Patient interviews were used during development and reduction of items, pilot testing and the psychometric study to assess content relevancy. The prototype instrument was reviewed by patients, 3 physical therapists, 1 physiatrist, 3 orthopedic surgeons and 2 research assistants. Patients and experts provided feedback on the appropriateness and wording of the items.

Structured content analysis was performed using 2 methods. The International Classification of Functioning Disability and Health (ICF) linking procedures were performed according to established linking rules $[27,28]$. ICF coding provides a common international language to describe the elements of body structure, function, disability and environment contained in questionnaire items. The Item Perspective Classification was used to perform a 2-level classification of type of decision (rational/ 
emotional) and content of items (psychological, social, biological, inorganic or pure experience). More detail on this coding method can be found at https://sites.google.com/ site/ipcframework/.

\section{Reliability}

A subset of patients was re-tested 2-7 days after their completing the PRUNE. The following statistics were calculated to establish the reliability of the PRUNE:

a) reliability intraclass correlation coefficients $(2,1)$ [29],

b) Standard error of measurement:

$$
\mathrm{SEM}=\text { standard deviation } \times \sqrt{1-\text { reliability coefficient }}
$$

and

c) Minimal detectable change (90\% confidence) $[30,31]$

$$
\mathrm{MDC}_{90}=\mathrm{SEM} \times \mathrm{z}-\text { value of } 1.64 \times \sqrt{2}
$$

\section{Structural validity}

Exploratory factor analyses (principal components analysis using varimax rotation) were used to assess how scale items distributed into subscales [32]. Analysis was performed on data collected at baseline which included a larger subset of items; and these results contributed to decisions about item reduction. Thus, the factor analysis performed at 3 and 24 months included only the final items.

\section{Construct validity}

The following hypotheses/expectations were constructed to assess construct validity of the PRUNE based on convergent relationships expected from theoretical and evidence perspectives [33,34]. The strength of these associations was assessed using Pearson correlations.

1. Scales measuring the same construct (pain or functional disability) should demonstrate high correlation (indicated by $\mathrm{r}>0.75$ )

2. Pain and function should moderately correlate (0.40$0.75)$

3. General health status would demonstrate low to moderate correlation with PRUNE subscale and total scores. PRUNE scores should correlate more highly with physical function than with mental function. Pain was expected to correlate with both physical and mental health status.

\begin{tabular}{|c|c|}
\hline Item & Rationale for exclusion/modification \\
\hline \multicolumn{2}{|l|}{ Deleted items } \\
\hline Pain during activity & Contamination of pain and function concepts within item \\
\hline Combing hair & Not appropriate to all respondents; higher level of missingness \\
\hline Using arms rise from a chair & Highly correlated to tying shoes; less responsive \\
\hline Pulling a heavy object & Correlated to lifting a heavy object; lifting a $10 \mathrm{~kg}$ weight \\
\hline Lifting a $10 \mathrm{~kg}$ weight & As above; not all respondents understand $10 \mathrm{~kg}$ \\
\hline Putting on a coat & Respondent feedback suggested less relevant; poor item performance overall \\
\hline Doing up buttons & $\begin{array}{l}\text { Cognitive interviews and task analysis suggests this item does not reflect sensory impairment } \\
\text { of the ulnar nerve- the concept of fine motor control was covered by finger use question }\end{array}$ \\
\hline \multicolumn{2}{|l|}{ Modified items } \\
\hline At night (while sleeping) & $\begin{array}{l}\text { Shift workers were not sure if at night meant during sleep or their night activity which was } \\
\text { work. Added ( while sleeping to clarify) }\end{array}$ \\
\hline Hold an object & $\begin{array}{l}\text { Item performance variable; however strong bio mechanical support and patient endorsement } \\
\text { that some type of holding object with arm bent was difficult. Qualitative interviews indicated } \\
\text { that respondents used a variety of reading devices and positions; and were not always clear } \\
\text { that it meant a continuous activity. Item modified to specify one hour interval and allow } \\
\text { multiple options for the object that was held clarifying that the elbow is bent }\end{array}$ \\
\hline Eating & Added specification of different eating utensils for cultural transferability \\
\hline Control of the small finger & $\begin{array}{l}\text { Different respondents use either small, little or fifth finger to indicate the fifth digit. Motor } \\
\text { dysfunction related to the ulnar comprise could include either deformity, lack of motor } \\
\text { control_ lay terms were used for these phenomena. }\end{array}$ \\
\hline Finger use & $\begin{array}{l}\text { Finger use was a common difficulty reported by patients. It was most remarkably noted for } \\
\text { keyboarding or musical instrument use but not all respondents perform these tasks therefore } \\
\text { the question was modified to: Repeated finger movement (like when typing, playing } \\
\text { instruments or moving small objects) }\end{array}$ \\
\hline
\end{tabular}

\section{Table 2 Items that did not meet inclusion in the final instrument version of the PRUNE}


Table 3 ICF codes for patient-rated ulnar nerve evaluation items

\begin{tabular}{ll}
\hline Pain items & \multicolumn{1}{c}{ ICF } \\
\hline Code(s) & b28014 - Pain in upper limb \\
When it is at its worst & \\
& \\
At rest & b28014 - Pain in upper limb \\
In the morning; \# & b28014 - Pain in upper limb \\
After work/activity\# & b28014 - Pain in upper limb \\
At night\# & b28014 - Pain in upper limb \\
How often do you have pain\# & b28014 - Pain in upper limb
\end{tabular}

\section{Other symptom items:}

Numbness in my little finger

"Pins and needles" in my little finger

Cramping or unable to control my little finger

Weakness in my hand (pinch/grip)

\section{Specific activities items}

Eat (use fork, knife, or chopsticks)

Lift a heavy object

Hold an object with my elbow bent (a telephone, tool, book, phone or electronic device)

Repeated reaching

Tasks with repetitive finger use -like typing, playing musical instruments or handling small objects

Turn a key/doorknob/handle

\section{Usual activities items}

Personal care activities (like washing, dressing)

Household (cleaning, maintenance) b265 or b280 - Sensation related to the skin

b760 - Control of voluntary movement functions

b7300 - Muscle power functions

d550 - Eating

d4300 - Lifting

d4401- Grasping

d4452 - Reaching

d440 - Fine hand use

d4453 - Turning or twisting the hands or arms

D5 - Chapter 5 Self-Care

D630-649 - Household tasks

Meaning in ICF language

Sensation of unpleasant feeling indicating potential or actual damage to some body structure felt in either one or both upper limbs, including hands.

Note: The descriptors of after work or while sleeping refer to a time point NOT an activity so they are not coded in ICF

Sensory functions of sensing surfaces and their texture or quality. Inclusions: functions of touching, feeling of touch impairments such as numbness, anaesthesia, tingling, paraesthesia and hyperaesthesia

Sensations related to the skin such as itching, burning sensation and tingling. Inclusions: impairments such as pins and needles sensation and crawling sensation

Functions associated with control over and coordination of voluntary movements. Inclusions: functions of control of simple voluntary movements and of complex voluntary movements, coordination of voluntary movements...

Functions related to the force generated by the contraction of a muscle or muscle groups. Inclusions: functions associated with the power of specific muscles and muscle groups, muscles of one limb, one side of the body, the lower half of the body, all limbs, the trunk and the body as a whole; impairments such as weakness of small muscles in feet and hands..

Carrying out the coordinated tasks and actions of eating food that has been served, bringing it to the mouth and consuming it in culturally acceptable ways, cutting or breaking food into pieces, opening bottles and cans, using eating implements, having meals, feasting or dining.

Raising up an object in order to move it from a lower to a higher level, such as when lifting a glass from the table.

Using one or both hands to seize and hold something, such as when grasping a tool or a door knob

Using the hands and arms to extend outwards and touch and grasp something, such as when reaching across a table or desk for a book

Performing the coordinated actions of handling objects, picking up, manipulating and releasing them using one's hand, fingers and thumb, such as required to lift coins off a table or turn a dial or knob. Inclusions: picking up, grasping, manipulating and releasing Exclusion: lifting and carrying objects (d430)

Using fingers, hands and arms to rotate, turn or bend an object, such as is required to use tools or utensils

Caring for oneself, washing and drying oneself, caring for one's body and body parts, dressing, eating and drinking, and looking after one's health

Range of tasks within domestic life that pertain to household but no specific group definition 
Table 3 ICF codes for patient-rated ulnar nerve evaluation items (Continued)

\begin{tabular}{lc}
\hline Work (your job or everyday work) & D8 - Chapter 8 Major Life Areas $\begin{array}{c}\text { Carrying out the tasks and actions required to engage in } \\
\text { education, work and employment and to conduct economic } \\
\text { transactions. }\end{array}$ \\
Recreational activities & $\begin{array}{c}\text { D920 - Recreation and leisure } \\
\text { Engaging in any form of play, recreational or leisure activity, } \\
\text { such as informal or organized play and sports, programmes } \\
\text { of physical fitness, relaxation, amusement or diversion, going } \\
\text { to art galleries, museums, cinemas or theatres; engaging in } \\
\text { crafts or hobbies, reading for enjoyment, playing musical } \\
\text { instruments; sightseeing, tourism and travelling for pleasure }\end{array}$ \\
&
\end{tabular}

\section{Constructed hypotheses for known-group validity}

The following known group differences were tested (by ANOVA) to assess construct validity of the PRUNE. The subgroups were defined by an independent assessor through patient interview and examination using criteria defined by Kleinman and Bishop [26].

1. Patients who perceived their global rating of change at 2 years as: improved, versus no change, or worse

2. Patient who were asymptomatic versus those who had mild-occasional, moderate, or severe symptoms

3. Patients who were able to return to work at their regular job versus those who are unable to work because of continued symptoms

4. Patients whose leisure was unlimited versus those who were limited

5. Patients who had both grip and pinch $80 \%$ of opposite hand versus those who had either grasp or pinch reach $80 \%$ of opposite hand versus those both where grip and pinch less than $80 \%$ of opposite hand

6. Patients who had normal sensibility defined as twopoint discrimination less than $5 \mathrm{~mm}$ versus those where it was abnormal greater than $5 \mathrm{~mm}$.

\section{Responsiveness}

Changes over time were evaluated by calculating a standardized response mean (change score divided by the standard deviation of the change scores) and effects size (change score divided by the standard deviation of the initial scores) [35].

\section{Results}

The final version is presented in Figure 1. Patients (See Table 1 for demographics) completed the PRUNE with few missing items $(<1.0 \%)$.

\section{Content validity}

A prototype 25 -item scale was developed based on items obtained item generation and early refinement procedures (expert and patient feedback). Subsequent item reduction of the 25-item prototype scale was based on statistical analyses and cognitive interviewing [36,37] Cognitive interviewing with patients indicated wide variability in interpretation (and use) in relation to the telephone item that led to modification of that item (Table 2).

ICF codes for the items are presented in Table 3. Pain items were coded to the ICF code for "Sensation of unpleasant feeling indicating potential or actual damage to some body structure felt in either one or both upper limbs, including hands (b28014). Concepts that relate to severity like frequency and intensity are not linked to ICF. Experts considered pain assessment fundamental to self-report and approved the range of qualifiers used for the pain items. The sensory motor subscale captures four separate ICF codes addressing touch function, sensation related to the skin; control of movement and muscle power. The Specific Activities Subscale was linked to six ICF disability codes at the third or fourth level and comprises codes that describe specific ADLs. The Usual Activity items coded to a high ICF level, i.e., chapter is consistent with the intent of this subscale to address broad domains of usual activity. In ICF language this subscale addresses self-care, household tasks, major life areas and recreation and leisure.

Using Item Perspective Classification all items were rational judgments because patients needed to recall information over the past week. Pain, symptoms and specific activities were classified as rational biological judgments. The first item of the usual activities subscale addresses personal care and hence falls under a rational judgment within the biological domain. The remaining three items (household, work and recreation) were classified as rational judgments about the social domain.

\section{Item behavior/distributions}

The full range of scores was used for all items except for numbness. The boxplots of items for each subscale at baseline (Figure $2 \mathrm{a}, \mathrm{b}, \mathrm{c}, \mathrm{d}$ and e).

The 6 pain items (Figure 2a) indicate that least and most pain items behaved as expected; with the remainder of items falling in a moderate range. From the sensory/motor symptoms subscale (labeled "Other Symptoms), numbness, pins and needles and weakness in the hand had high overall ratings; whereas, the motor control item was less severely affected. Numbness was the only item not endorsed by some individuals. Item responses for baseline specific functional activities (Figure 2b) indicated that "Carrying a heavy 


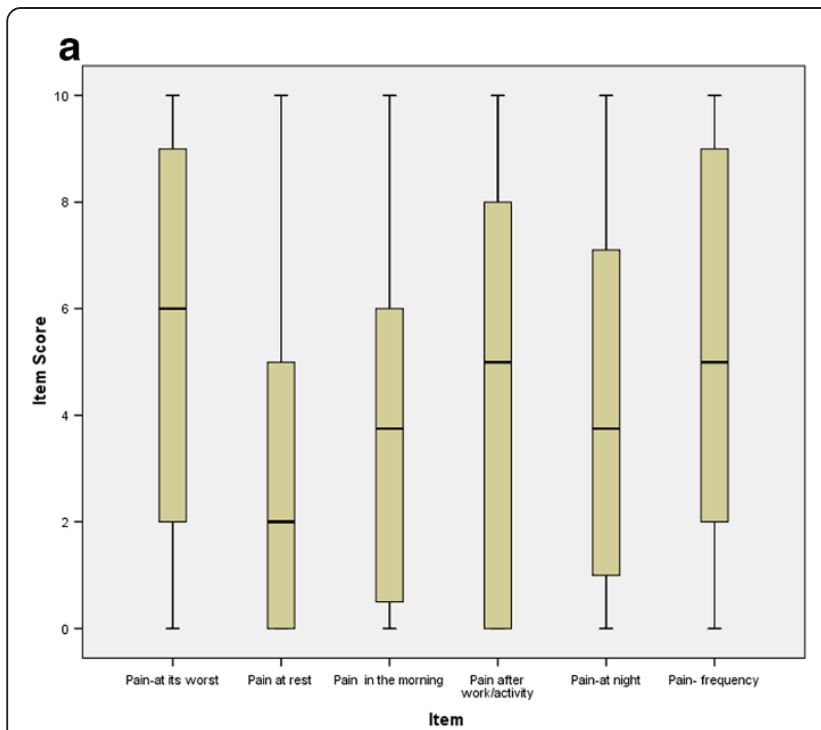

\section{b}

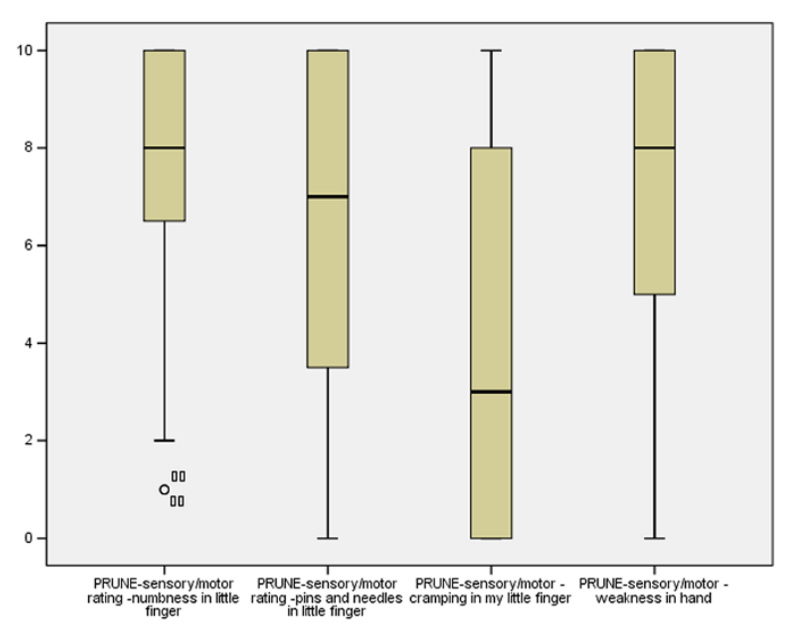

C

d
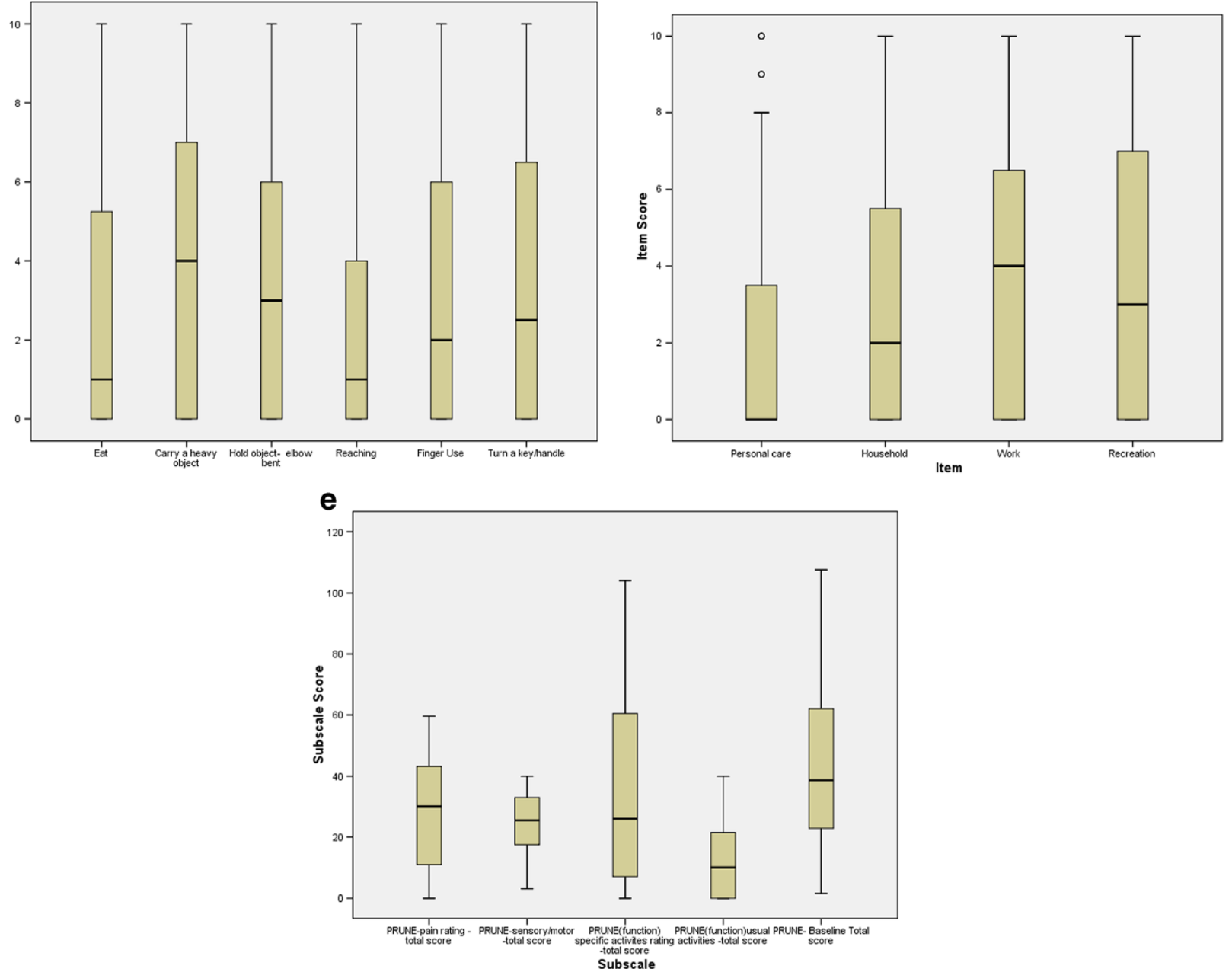

Figure 2 Boxplots of subscale items at baseline. a: Boxplot of Pain Items. b: Boxplot of Sensory/motor Symptoms Subscale. c: Boxplot of Items in Specific Activity Subscale. d: Boxplots of Items in Usual Activity Subscale. e: Boxplot of Subscale and Total Scores of Baseline PRUNE. 
Table 4 Reliability of PRUNE subscales and total scores

\begin{tabular}{lccccccccc}
\hline Subscale & $\begin{array}{c}\text { Mean score } \\
\text { test }\end{array}$ & $\begin{array}{c}\text { Test } \\
\text { SD }\end{array}$ & $\begin{array}{c}\text { Mean score } \\
\text { retest }\end{array}$ & $\begin{array}{c}\text { Re-test } \\
\text { SD }\end{array}$ & ICC & 95\% Cl & $\begin{array}{c}\text { Standard error of } \\
\text { measurement (SEM) }\end{array}$ & $\begin{array}{c}\text { SEM\% } \\
\text { Minimum detectable } \\
\text { change (MDC) }\end{array}$ \\
\hline Pain/60 & 25.1 & 17.3 & 25.0 & 18.0 & 0.98 & $0.91-0.99$ & 2.5 & 4 & 5.8 \\
Sensori-motor & 12.6 & 7.9 & 14.0 & 9.8 & 0.91 & $0.70-0.98$ & 2.7 & 7 & 6.2 \\
symptoms/40 & & & & & & & & & 10 \\
Specific activities/40 & 35.7 & 31.9 & 36.0 & 30.5 & 0.99 & $0.97-0.999$ & 3.1 & 8 & 7.3 \\
Usual activities/40 & 10.8 & 13.2 & 13.4 & 13.0 & 0.87 & $0.57-96$ & 4.7 & 11 & 11.0 \\
Total Score/100 & 34.4 & 21.5 & 36.0 & 23.1 & 0.98 & $0.95-0.997$ & 3.1 & 3 & 7.2 \\
\hline
\end{tabular}

$S D$, Standard deviation; ICC, Intraclass correlation coefficient; $\mathrm{Cl}$, Confidence interval. A random sample of patients and visits were selected to do a retest questionnaire in 2-7 days. The \% of SEM and MDC as a proportion of scale allows for comparability of these across different sized subscales.

object" and holding an object with the arm bent were difficult tasks; whereas, eating and use of the telephone had lower ratings. Work was the most difficult "usual activity".

The subscale and total scores distributions and indicators of central tendency are reported in boxplots 2e. These illustrate that subscales are normally distributed.

\section{Reliability}

High ICCs were obtained with all subscales exceeding 0.90 except for usual activities (0.87). The ICC was 0.98 for the total score. Lower limits of the confidence interval were high with the exception of usual activities where the confidence interval was wide (Table 4). The standardized response mean (SEM) and Minimal Detectable Change (MDC) were 3.1 and 7.2 respectively for the total score (Table 4).

\section{Construct validity}

The PRUNE was highly discriminative between different functional outcomes across all of the defined subgroups (See Tables 5 and 6). The follow-up scores were significantly different between subgroups based on whether they were working or not (16.5 vs. 53.8), able to do their normal activities or not (10.8 vs. 37.8$)$ or had 2-point

Table 5 Construct validity indicated by binary clinical subgroups at 24 months

\begin{tabular}{|c|c|c|c|c|c|}
\hline \multirow{3}{*}{$\frac{\text { Clinically meaningful subgrouping }}{\text { Work status }}$} & \multirow[t]{3}{*}{ Subscale } & \multicolumn{4}{|c|}{ Scores } \\
\hline & & \multicolumn{2}{|c|}{$\begin{array}{c}\text { Not working because of ulnar } \\
\text { neuropathy }(n=9)\end{array}$} & \multicolumn{2}{|c|}{$\begin{array}{l}\text { Working or able to work at } \\
\text { previous job }(n=34)\end{array}$} \\
\hline & & Mean & SD & Mean & SD \\
\hline & Total score & 53.8 & 14.6 & 16.5 & 16.2 \\
\hline & Pain & 34.1 & 16.1 & 11.2 & 12.5 \\
\hline & Symptoms & 27.8 & 12.0 & 11.6 & 10.7 \\
\hline & Specific activities & 48.4 & 12.7 & 13.0 & 16.9 \\
\hline & Usual activities & 19.9 & 7.0 & 5.4 & 8.7 \\
\hline \multirow[t]{7}{*}{ Ability to do activities } & & \multicolumn{2}{|c|}{ Limited $(n=25)$} & \multicolumn{2}{|c|}{ Not limited (n-27) } \\
\hline & & Mean & SD & Mean & SD \\
\hline & Total score & 37.8 & 18.0 & 10.8 & 12.0 \\
\hline & Pain & 23.0 & 16.7 & 8.8 & 8.9 \\
\hline & Symptoms & 20.6 & 11.6 & 8.1 & 9.1 \\
\hline & Specific activities & 34.5 & 22.7 & 4.9 & 13.3 \\
\hline & Usual activities & 15.0 & 8.3 & 1.7 & 2.5 \\
\hline \multirow[t]{7}{*}{ Sensibility } & & \multicolumn{2}{|c|}{ Abnormal (> $5 \mathrm{~mm})(\mathrm{n}-14)$} & \multicolumn{2}{|c|}{ Normal $(n=28)$} \\
\hline & & Mean & SD & Mean & SD \\
\hline & Total score & 26.8 & 24.2 & 21.9 & 21.4 \\
\hline & Pain & 16.3 & 17.9 & 18.4 & 15.3 \\
\hline & Symptoms & 22.0 & 12.5 & 10.9 & 11.8 \\
\hline & Specific activities & 25.5 & 27.0 & 15.4 & 19.3 \\
\hline & Usual activities & 10.1 & 10.6 & 7.1 & 9.3 \\
\hline
\end{tabular}


Table 6 Differences between clinically meaningful subgroups

\begin{tabular}{|c|c|c|c|c|c|c|c|c|c|}
\hline \multirow{3}{*}{$\begin{array}{l}\text { Clinically meaningful subgroups } \\
\text { Overall change following surgery }\end{array}$} & \multirow[t]{3}{*}{ Subscale } & \multicolumn{8}{|c|}{ Scores } \\
\hline & & \multicolumn{2}{|c|}{ Worse $(n=6)$} & \multicolumn{4}{|c|}{ Unchanged $(n=9)$} & \multicolumn{2}{|c|}{ Better $(n=45)$} \\
\hline & & Mean & SD & Me & & & & Mean & SD \\
\hline & Total score & 46.7 & 19.3 & 43 & & & & 14.1 & 17.1 \\
\hline & Pain & 28.6 & 22.6 & 20 & & & & 9.9 & 12.9 \\
\hline & Symptoms & 27.1 & 13.3 & 27 & & & & 8.9 & 9.9 \\
\hline & Specific activities & 40.8 & 28.8 & 35 & & & & 10.9 & 18.8 \\
\hline & Usual activities & 16.8 & 4.3 & 12 & & & & 5.4 & 9.4 \\
\hline \multirow[t]{7}{*}{ Hand strength } & & \multicolumn{2}{|c|}{$\begin{array}{c}\text { Both grip and pinch }<80 \% \\
\text { of opposite hand }(n=8)\end{array}$} & \multicolumn{4}{|c|}{$\begin{array}{c}\text { Either grip or pinch }<80 \% \\
\text { of opposite hand }(n=7)\end{array}$} & \multicolumn{2}{|c|}{$\begin{array}{l}\text { Grip and pinch both }>80 \% \\
\text { of opposite hand }(n=25)\end{array}$} \\
\hline & & Mean & SD & Me & & & & Mean & SD \\
\hline & Total score & 33.1 & 18.6 & 22 & & & & 14.8 & 16.7 \\
\hline & Pain & 20.8 & 16.4 & 16 & & & & 13.4 & 9.4 \\
\hline & Symptoms & 19.0 & 14.1 & 13 & & & & 9.8 & 9.5 \\
\hline & Specific activities & 24.8 & 39.7 & 20 & & & & 11.2 & 18.2 \\
\hline & Usual activities & 13.2 & 11.1 & 9. & & & & 5.3 & 7.6 \\
\hline \multirow[t]{7}{*}{ Residual symptoms } & & \multicolumn{2}{|c|}{ Severe } & \multicolumn{2}{|c|}{ Moderates } & \multicolumn{2}{|c|}{ Mild occasional } & \multicolumn{2}{|c|}{ Asymptomatic } \\
\hline & & Mean & SD & Mean & SD & Mean & SD & Mean & SD \\
\hline & Total score & 61.1 & 29.0 & 40.4 & 17.7 & 17.3 & 14.5 & 6.6 & 16.0 \\
\hline & Pain & 39.6 & 24.7 & 26.9 & 15.3 & 10.7 & 10.7 & 4.8 & 10.7 \\
\hline & Symptoms & 33.8 & 9.3 & 23.3 & 10.8 & 11.7 & 9.5 & 4.3 & 11.4 \\
\hline & Specific activities & 54.4 & 3.4 & 34.0 & 25.0 & 11.7 & 16.0 & 5.0 & 2.6 \\
\hline & Usual activities & 19.0 & 9.9 & 18.2 & 9.4 & 4.6 & 6.8 & 1.1 & 2.7 \\
\hline
\end{tabular}

Although there were variations between subsets of scores; there was a significant linear trend across all scores; patients in the best clinical outcome category always were significantly better than the lowest clinical outcome category regardless of the subscale $(p<0.01)$.

discrimination $<5 \mathrm{~mm}$ or not (21.9 vs. 26.8). People who reported their scores were the same or worse after surgery had PRUNE scores over 40 at follow-up; whereas, those who reporting being better had a score of 14.1 (see Tables 5 and 6 for subgroup scores). There was a linear trend to PRUNE scores based on whether patients reported mild to severe disability (Figure 3 ).

Correlations coefficients were more strongly associated with the physical health domains on the SF-36 in comparison to the mental health domains (Table 7). The sensory/ motor symptoms subscale correlated most strongly with overall physical health status indicating the importance of the ulnar nerve symptom items. Stronger correlations were observed between more conceptually similar subscales of the PRUNE and SF-36. All of these findings supported the construct validity.

\section{Factor validity}

The baseline factor analysis included the items from the longer version of the PRUNE (before final item reduction). Items dispersed into 4 factors representing pain, symptoms, specific function and usual functions at baseline (Table 8). At baseline, the larger subscales (pain-24\% and specific activity-25\%) explained the largest portion of the variance. The smaller subset of final items included in the 3 and 24 month factor analysis also loaded on these same 4 factors (See Table 9). Pain explained more than $20 \%$ of the variance at 3 and 24 months. Although the item "weakness in the hand" loaded most strongly on its assigned subscale (sensory/motor symptoms function), it exhibited some cross-loading onto Specific Activity. At 24 months recreational activities cross loaded on pain, and specific activity- although its highest loading was on Usual Activity. Overall, factor analysis supported the structural validity of the subscales.

\section{Responsiveness}

A large effect size (and standardized response mean) was observed from baseline to 24 months (Table 10) for all subscales (all SRM $<0.90)$ and the total score $(\mathrm{SRM}=1.55)$.

\section{Discussion}

This study provides evidence that the PRUNE is capable of providing reliable, valid and responsive assessment of symptoms and function experienced by patients with ulnar nerve compression.

Content validity analyses supported the theoretical content of the PRUNE. ICF linking indicated that the PRUNE 


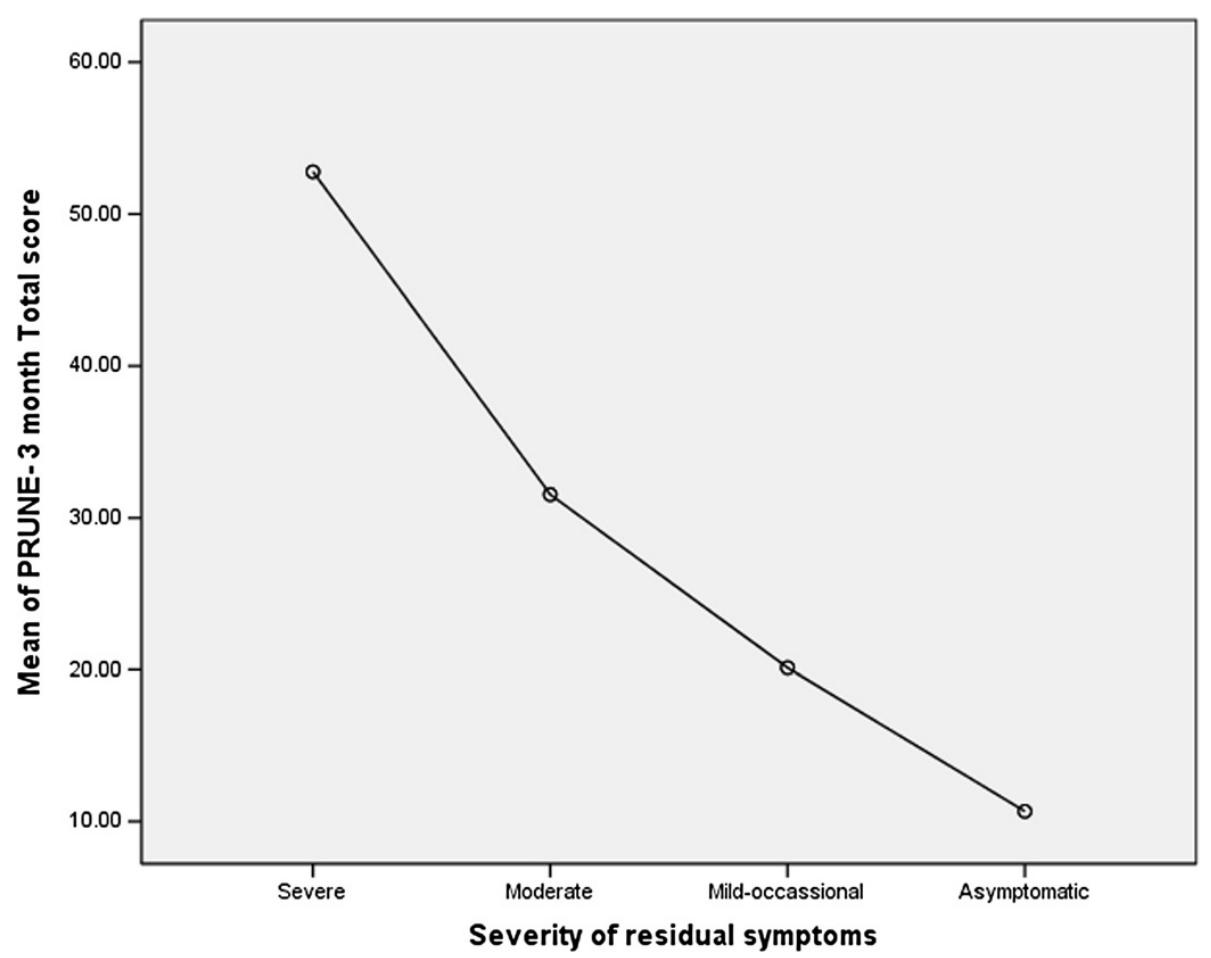

Figure 3 PRUNE symptom score at 3 months post-op.

crosses a number of domains of the ICF. The sensory/ motor symptoms scale items linked to ICF codes for touch function, sensation related to the skin, control of movement and muscle power which is a fit with the conceptual target to measure symptoms arising from ulnar nerve compression symptoms. Use of patients, experts, ICF coding and cognitive content coding provided a comprehensive assessment of the content validity of the PRUNE. Given that content validity is the most foundational element of scale validity, it is critical that content issues be rigorously evaluated and resolved before proceeding to more statistically based clinical measurement evaluations. The extent of content validation performed for this study exceeds previous instrument development which is related to the development of clinical measurement methods for ICF linking and use of cognitive interviews in measure development.

Table 7 Construct validity indicated by PRUNE scores to general health status subscales

\begin{tabular}{|c|c|c|c|c|c|}
\hline \multirow[b]{2}{*}{ SF- 36 subscale } & \multicolumn{5}{|c|}{ PRUNE score (2-year) } \\
\hline & Pain & SM symptoms & Specific activities & Usual activity & Total score \\
\hline & 76 & 76 & 75 & 75 & 76 \\
\hline SF36 - 2-Physical Functioning Subscale & $-0.5^{* *}$ & $-0.46^{* *}$ & $-0.39^{* *}$ & $-0.36^{* *}$ & $-0.52^{* *}$ \\
\hline SF36 - 2 -Role -Physical Subscale & $-0.35^{* *}$ & $-0.41^{* *}$ & -0.16 & 0.08 & -0.25 \\
\hline SF36 - 2-Bodily Pain Subscale & $-0.59^{* *}$ & $-0.68^{* *}$ & $-0.53^{* *}$ & $-0.35^{* *}$ & $-0.64^{* *}$ \\
\hline SF36- 2 -General Health Subscale & $-0.33^{*}$ & $-0.34^{* *}$ & -0.19 & -0.25 & $-0.33^{*}$ \\
\hline SF36 - 2-Vitality Subscale & $-0.48^{* *}$ & $-0.37^{* *}$ & -0.21 & -0.12 & $-0.36^{* *}$ \\
\hline SF36 - 2 -Social Functioning Subscale & $-0.60^{* *}$ & $-0.45^{* *}$ & $-0.31^{*}$ & -0.09 & $-0.45^{* *}$ \\
\hline SF36 - 2 -Role- Emotional Subscale & $-0.39^{* *}$ & $-0.41^{* *}$ & $-0.30^{*}$ & -0.16 & $-0.38^{* *}$ \\
\hline SF36 - 2 -Mental Health Subscale & $-0.34^{* *}$ & -0.19 & -0.20 & -0.07 & -0.25 \\
\hline SF36 - 2 -Physical Component Summary & $-0.58^{* *}$ & $-0.68^{* *}$ & $-0.42^{* *}$ & $-0.32^{*}$ & $-0.59^{* *}$ \\
\hline SF36 - 2 -Mental Component Summary & $-0.37^{* *}$ & -0.23 & -0.19 & -0.004 & -0.25 \\
\hline
\end{tabular}

Pearson correlations between subscales, or the total score of the PRUNE, and the subscales of the SF-36 obtained at follow-up indicate that pain, sensory/motor (SM) symptoms and total scores were consistently moderately correlated with the SF-36 physical subscales or summary score. The sensory/motor symptoms subscale correlated most strongly with overall physical health status. The bolded scores in each column show where the stronger relationships existed. (Correlations who are significant at $p<0.05$ are noted as ${ }^{*}$, and those where $p<0.01$ are noted as ${ }^{* *}$.) 
Table 8 Factor analysis of the extended version of the baseline PRUNE and contribution to item reduction

\begin{tabular}{|c|c|c|c|c|c|}
\hline \multirow{2}{*}{$\begin{array}{l}\text { Items on baseline longer } \\
\text { version of PRUNE } \\
\text { (before final item reduction) }\end{array}$} & \multicolumn{4}{|c|}{ Subscale } & \multirow{2}{*}{$\begin{array}{r}\text { Explanation of final decisions on items deleted from } \\
\text { the final scale during production processes }\end{array}$} \\
\hline & Pain & $\begin{array}{r}\text { Usual } \\
\text { activity /role }\end{array}$ & $\begin{array}{l}\text { Specific } \\
\text { activity }\end{array}$ & $\begin{array}{r}\text { Sensory } / \text { motor } \\
\text { symptoms }\end{array}$ & \\
\hline Variance Explained by factor (\%) & 24 & 15 & 26 & 10 & $\begin{array}{l}\text { Although some items cross loaded as below; the largest } \\
\text { amount of variance was by specific activity items; } \\
\text { followed by pain, usual activity and sensory/motor symptoms }\end{array}$ \\
\hline Pain - At its worst & 0.86 & 0.12 & 0.26 & 0.12 & \\
\hline Pain - At Rest & 0.76 & 0.21 & 0.36 & 0.02 & \\
\hline Pain - Morning & 0.74 & 0.28 & 0.33 & 0.26 & \\
\hline Pain - During activity & 0.70 & 0.29 & 0.51 & 0.26 & Pain during activity was dropped from the reduced measure \\
\hline Pain - After activity & 0.85 & 0.15 & 0.24 & 0.19 & \\
\hline Pain - At night & 0.83 & 0.20 & 0.25 & 0.02 & \\
\hline Pain - Frequency & 0.89 & 0.19 & 0.11 & 0.16 & \\
\hline SM - Numbness & 0.37 & 0.74 & -0.02 & 0.24 & Hand weakness cross loads but left as a component of \\
\hline SM - Pins And needles & 0.27 & 0.76 & 0.18 & -0.04 & $\begin{array}{l}\text { sensory/motor symptoms scale given importance. Motor } \\
\text { Control item clarified based on respondent feedback }\end{array}$ \\
\hline SM - Control finger & 0.14 & 0.78 & 0.23 & 0.13 & \\
\hline SM - Weakness in hand & 0.46 & 0.47 & 0.06 & 0.46 & \\
\hline SA - Combing hair & 0.32 & 0.25 & 0.78 & 0.29 & $\begin{array}{r}\text { Hair combing deleted: not applicable to a number } \\
\text { of respondents }\end{array}$ \\
\hline SA - Eating & 0.15 & 0.40 & $\underline{0.67}$ & 0.30 & \\
\hline SA - Lift heavy object & 0.34 & 0.18 & 0.72 & 0.31 & \\
\hline SA - Finger task & $\underline{0.49}$ & 0.04 & $\underline{0.66}$ & 0.37 & \\
\hline SA - Pull & $\underline{0.43}$ & 0.12 & $\underline{0.39}$ & $0 . \underline{52}$ & $\begin{array}{r}\text { Pulling deleted due to cross loading and correlation } \\
\text { with heavy lifting }\end{array}$ \\
\hline SA - Throw a small object & 0.32 & 0.10 & $\underline{0.81}$ & 0.24 & Throwing deleted due to higher rate of missingness \\
\hline SA - Use a telephone & 0.39 & 0.00 & $\underline{0.73}$ & 0.26 & \\
\hline SA - Doing up buttons & 0.12 & 0.25 & $\underline{0.59}$ & 0.21 & Doing buttons and washing deleted based on cross \\
\hline SA - Wash opposite armpit & 0.30 & 0.11 & $\underline{0.73}$ & 0.26 & \\
\hline SA - Reaching & 0.35 & 0.01 & $\underline{0.82}$ & 0.15 & \\
\hline SA - Turning a doorknob & 0.19 & 0.08 & 0.69 & 0.45 & \\
\hline UA - Personal care & -0.02 & 0.06 & 0.40 & 0.60 & \\
\hline UA - Household & 0.11 & 0.14 & 0.41 & 0.68 & \\
\hline UA - Work & 0.14 & 0.08 & 0.27 & 0.85 & \\
\hline UA - Recreational activities & 0.22 & 0.12 & 0.37 & 0.77 & \\
\hline
\end{tabular}

Principal Component Analysis with Varimax with Kaiser Normalization for items in the longer version of the PRUNE before the final item reductions were completed. Factor loadings are color-coordinated to highlight loading over 0.40 . (Pain subscale items in bold, sensory/motor symptoms items in italics, specific activity items in underline (SA) and usual activity items in bolde (UA). Cross loading occurred on a number of items and was one issue considered in the item reduction process (along with the cross correlation between items, and results of patient interviews with respect to item interpretation and clarity).

Box plots indicated that the full range of scores was endorsed on almost every item. However, there were no participants who reported having "zero" numbness indicating that this was a consistent UNE symptom. Sensory symptoms (numbness and tingling) were rated as being more severe than motor control of the little finger. This is consistent with the pathology of nerve compression where sensory changes are an early impairment and motor changes occur with more severe or prolonged compression [38].
A reliability coefficient of 0.90 has been recommended for measures to be used on individual patients [39]; whereas greater than 0.75 is considered excellent for group comparisons [40]. The reliability of the total score or subscales scores of the PRUNE were all high, indicating either total or component scores could be used to make decisions about individual patients. A minimal detectable change of approximately 7 points for the total score suggests that clinicians should be confident that the PRUNE has indicated a true change in symptoms and disability when the score 
Table 9 Results of factor analysis of the final PRUNE items at 3 and 24 months after surgery

\begin{tabular}{|c|c|c|c|c|c|c|c|c|}
\hline \multirow[t]{2}{*}{ Items on Final PRUNE } & \multicolumn{4}{|c|}{3 months after surgery } & \multicolumn{4}{|c|}{24 months after surgery } \\
\hline & Pain & $\begin{array}{r}\text { Usual } \\
\text { activity/role }\end{array}$ & $\underline{\text { Specific activity }}$ & SM symptoms & Pain & $\begin{array}{r}\text { Usual } \\
\text { activity/role }\end{array}$ & Specific activity & SM symptoms \\
\hline Variance explained by factor (\%) & 22 & 16 & $\underline{20}$ & 21 & 30 & 19 & $\underline{18}$ & 18 \\
\hline Pain- worst & 0.82 & 0.09 & 0.34 & 0.17 & 0.84 & 0.25 & 0.26 & 0.27 \\
\hline Pain-at rest & 0.86 & 0.38 & 0.14 & 0.23 & 0.83 & -0.12 & 0.32 & 0.38 \\
\hline Pain -in morning & 0.77 & 0.38 & 0.27 & 0.14 & 0.86 & 0.09 & 0.25 & 0.32 \\
\hline Pain -after activity & 0.63 & 0.28 & 0.26 & 0.16 & 0.74 & 0.13 & 0.29 & 0.27 \\
\hline Pain- at night & 0.89 & 0.17 & 0.10 & 0.23 & 0.80 & 0.04 & 0.34 & 0.33 \\
\hline Pain- Frequency & 0.68 & 0.14 & 0.24 & 0.36 & 0.71 & 0.21 & 0.21 & 0.34 \\
\hline SM-Numbness & 0.06 & 0.26 & 0.19 & 0.86 & 0.36 & 0.19 & 0.15 & 0.87 \\
\hline SM-Pins and needles & 0.24 & 0.25 & 0.10 & 0.82 & 0.39 & 0.25 & 0.20 & 0.80 \\
\hline SM-Control & 0.36 & -0.00 & 0.17 & 0.77 & 0.33 & 0.04 & 0.23 & 0.68 \\
\hline SM-Weakness in hand & 0.06 & 0.15 & 0.44 & 0.69 & 0.34 & 0.37 & 0.48 & 0.59 \\
\hline$\underline{\text { SA-Eating with fork or spoon }}$ & 0.30 & 0.26 & $\underline{0.60}$ & $\underline{0.10}$ & -0.02 & 0.88 & $\underline{0.66}$ & 0.196 \\
\hline$\underline{\text { SA- Lift a heavy object }}$ & 0.23 & 0.22 & $\underline{0.78}$ & $\underline{0.14}$ & 0.38 & 0.44 & $\underline{0.58}$ & 0.25 \\
\hline$\underline{\text { SA-Hold an object }}$ & 0.30 & 0.47 & $\underline{0.58}$ & $\underline{0.26}$ & 0.37 & 0.123 & $\underline{0.88}$ & 0.14 \\
\hline$\underline{\text { SA- Finger Task }}$ & 0.32 & 0.02 & $\underline{0.78}$ & $\underline{0.24}$ & 0.36 & 0.38 & $\underline{0.60}$ & 0.37 \\
\hline$\underline{\text { SA-Reaching }}$ & 0.23 & 0.22 & $\underline{0.78}$ & $\underline{0.14}$ & 0.45 & 0.36 & $\underline{0.59}$ & 0.31 \\
\hline$\underline{\text { SA-Turning a doorknob }}$ & 0.10 & 0.30 & $\underline{0.70}$ & $\underline{0.35}$ & 0.20 & 0.30 & $\underline{0.68}$ & 0.25 \\
\hline UA-Personal care & 0.09 & 0.84 & 0.05 & 0.34 & -0.02 & 0.89 & 0.27 & 0.06 \\
\hline UA-Household & 0.32 & 0.76 & 0.25 & 0.35 & 0.28 & 0.52 & 0.45 & 0.11 \\
\hline UA-Work & 0.35 & 0.78 & 0.34 & 0.00 & 0.32 & 0.68 & 0.26 & 0.06 \\
\hline UA-Recreational activities & 0.36 & 0.78 & 0.36 & 0.19 & 0.44 & 0.58 & 0.48 & 0.21 \\
\hline
\end{tabular}

Principal Component Analysis with Varimax with Kaiser Normalization. Factor loadings are color-coordinated to highlight loading over 0.40. (Pain subscale items in bold, sensory/motor (SM) symptoms items in italics (SM), specific activity items in underline (SA) and usual activity items in bold (UA). Overall, cross loading was minimal and items differentiated onto the anticipated subscales. Cross loading occurred for item on weakness in grip at both 3- and 24- month follow-up. At 2-year follow-up heavy object and recreational activities also demonstrated some cross-loading. Overall, the loading confirmed the subscale structure.

changes by this amount. Some have suggested that a MDC of less than $10 \%$ of the score range is excellent. Whether the ICC, SEM or MDC are used to indicate reliability the PRUNE demonstrated high reliability. We speculate that test-retest reliability can be influenced by the retest interval, the number of items on a subscale, the acuity of the patients tested; and the extent to which the

Table 10 Standardized response means for improvement in PRUNE total and subscale scores from baseline to $\mathbf{2 4}$ months

\begin{tabular}{llll}
\hline Subscale & Mean change & SD & $\begin{array}{l}\text { Standardized } \\
\text { response mean }\end{array}$ \\
\hline Pain & 18.8 & 19.4 & 0.96 \\
Sensory/motor symptoms & 11.8 & 11.3 & 1.0 \\
Specific activities & 17.0 & 16.2 & 1.04 \\
Usual activities & 12.9 & 12.0 & 0.92 \\
Total score & 34.3 & 19.5 & 1.55 \\
\hline
\end{tabular}

construct being measured is stable and definable by patients. For example, the "usual" activities performed over the past 24 hours can vary and influence how people calibrate that item even when the patient's condition is stable.

Structural validity was supported by factor analysis that indicated the items fell into 4 subscales that matched the proposed structure. Only minor cross-loading was found. Pain explained more than $20 \%$ of the variance at all time points. The confirmation that pain and sensory/motor symptoms systems were separate concepts in the response patterns is important as it verifies the importance of an ulnar nerve specific measure which goes beyond pain questions to capture these additional more disease-specific symptoms.

The known groups validity supported the ability of the PRUNE to discriminate between different clinical subgroups like those who have/have not improved following surgery, or able/not able to return to work. Known group differences can be useful clinically as benchmark comparison scores when assessing whether patient profiles match 
different categories of outcome. There were 10 -fold differences in score between those who rated themselves as asymptomatic versus those who experienced severe symptoms; and a linear pattern was present for the scores for mild, moderate and severe rating. This suggests that increasing PRUNE scores reflect a linear trend of worsening outcomes that mirrors patient and clinician outcome ratings.

The construct validity of the scale was supported since the observed correlations matched the expected convergent relationships. The stronger relationships would be observed between PRUNE subscales and physical subscales of the SF-36 was expected and confirmed. We also anticipated that pain might interfere with social roles which was also confirmed. However, overall, the PRUNE demonstrated low correlation to mental health status which is consistent with its focus on the physical symptoms of UNE.

Finally, the large effect sizes observed in measuring change over time supports the responsiveness of the PRUNE to detect change over time, i.e., following treatment. This is an important measurement feature because assessing change in response to treatment is the most predominant use of outcome measures. A previous study demonstrated a smaller (moderate) effect size for a different PRO, although the intervention was conservative management in that study [14]. Others have cautioned that responsiveness can vary by treatment [35] and thus it would be premature to state that the PRUNE is more responsiveness than this measure.

\section{Conclusion}

This study led to the development of a reliable and valid measurement tool designed specifically for the patient population with ulnar nerve pathology. The next steps in evaluating the PRUNE should include analysis of the measurement properties through Rasch analysis which would address scale and differential item functioning issues (e.g. gender or age effects) not addressed in this study; and analysis of its responsiveness to detect clinical change in head-to-head comparison against other outcome measures. The PRUNE is provided by open access from the developer/copyright owner (J MacDermidjmacderm@uwo.ca) for free use.

\section{Competing interests}

The authors declare that they have no competing interests.

\section{Authors' contributions}

JMD developed the Patient-Rated Ulnar Nerve Evaluation, designed the psychometric study, provided oversight to all data collection, conducted the study analyses and wrote the initial drafts of the paper. RG enrolled patients, reviewed data analysis and contributed to revisions of the manuscript. All authors read and approved the final manuscript.

Received: 24 August 2012 Accepted: 10 April 2013

Published: 26 April 2013

\section{References}

1. Latinovic R, Gulliford MC, Hughes RA: Incidence of common compressive neuropathies in primary care. J Neurol Neurosurg Psychiatry 2006, 77:263-265.

2. Mondelli M, Giannini F, Ballerini M, Ginanneschi F, Martorelli E: Incidence of ulnar neuropathy at the elbow in the province of Siena (Italy). J Neurol Sci 2005, 234:5-10.

3. Descatha A, Leclerc A, Chastang JF, Roquelaure $Y$ : Incidence of ulnar nerve entrapment at the elbow in repetitive work. Scand J Work Environ Health 2004, 30:234-240.

4. van Rijn RM, Huisstede BM, Koes BW, Burdorf A: Associations between work-related factors and specific disorders at the elbow: a systematic literature review. Rheumatology (Oxford) 2009, 48:528-536.

5. Patterson JM, Jaggars MM, Boyer Ml: Ulnar and median nerve palsy in longdistance cyclists. A prospective study. Am J Sports Med 2003, 31:585-589.

6. Pellieux S, Fouquet B, Lasfargues G: Ulnar nerve tunnel syndrome of the elbow and an occupational disorder. Analysis of socio-professional and physical parameters. Ann Readapt Med Phys 2001, 44:213-220.

7. Bartels $\mathrm{RH}$, Verbeek AL: Risk factors for ulnar nerve compression the elbow: a case control study. Acta Neurochir (Wien) 2007, 149:669-674.

8. Caliandro P, La TG, Padua R, Giannini F, Padua L: Treatment for ulnar neuropathy at the elbow. Cochrane Database Syst Rev 2011 (2):CD006839.

9. Shi Q, MacDermid JC, Santaguida PL, Kyu HH: Predictors of surgical outcomes following anterior transposition of ulnar nerve for cubital tunnel syndrome: a systematic review. J Hand Surg Am 2011, 36:1996-2001

10. McCormick CA, Rath S, Patra PN, Pereira J, Wilkinson M: A qualitative study of common functional problems experienced by people with complete ulnar nerve paralysis. Lepr Rev 2008, 79:154-161.

11. Novak CB, Mackinnon SE, Stuebe AM: Patient self-reported outcome after ulnar nerve transposition. Ann Plast Surg 2002, 48:274-280.

12. Macadam SA, Bezuhly M, Lefaivre KA: Outcomes measures used to assess results after surgery for cubital tunnel syndrome: a systematic review of the literature. J Hand Surg Am 2009, 34:1482-1491.

13. Longo UG, Franceschi F, Loppini M, Maffulli N, Denaro V: Rating systems for evaluation of the elbow. Br Med Bull 2008, 87:131-161.

14. Mondelli M, Padua L, Giannini F, Bibbo G, Aprile I, Rossi S: A selfadministered questionnaire of ulnar neuropathy at the elbow. Neuro/ Sci 2006, 27:402-411.

15. Levine DW, Simmons SP, Koris MJ, Daltroy LH, Hohl GG, Fossel AH, et al: A self-administered questionnaire for assessment of severity of symptoms and functional status in carpal tunnel syndrome. J Bone Joint Surg Am 1993, 75A:1585-1592.

16. MacDermid JC: Development of a scale for patient rating of wrist pain and disability. J Hand Ther 1996, 9:178-183.

17. MacDermid JC, Turgeon T, Richards RS, Beadle M, Roth JH: Patient rating of wrist pain and disability: a reliable and valid measurement tool. J Orthop Trauma 1998, 12:577-586.

18. MacDermid JC: Outcome evaluation in patients with elbow pathology: issues in instrument development and evaluation. J Hand Ther 2001, 14:105-114

19. MacDermid J: Update: the patient-rated forearm evaluation questionnaire is now the patient-rated tennis elbow evaluation. J Hand Ther 2005, 18:407-410.

20. Shi Q, MacDermid J, Grewal R, King GJ, Faber K, Miller TA: Predictors of functional outcome change 18 months after anterior ulnar nerve transposition. Arch Phys Med Rehabil 2012, 93:307-312.

21. Bartels RH, Menovsky T, Van Overbeeke JJ, Verhagen WI: Surgical management of ulnar nerve compression at the elbow: an analysis of the literature. J Neurosurg 1998, 89:722-727.

22. Davis GA, Bulluss KJ: Submuscular transposition of the ulnar nerve: review of safety, efficacy and correlation with neurophysiological outcome. J Clin Neurosci 2005, 12:524-528.

23. Amadio PC, Silverstein MD, Ilstrup DM, Schleck CD, Jensen LM: Outcome after colles fracture: the relative responsiveness of three questionnaires and physical examination measures. J Hand Surg Am 1997, 21:781-787.

24. MacDermid JC, Richards RS, Donner A, Bellamy N, Roth JH: Responsiveness of the short form-36, disability of the arm, shoulder, and hand questionnaire, patient-rated wrist evaluation, and physical impairment measurements in evaluating recovery after a distal radius fracture. $J$ Hand Surg Am 2000, 25:330-340. 
25. Beaton DE, Bombardier C, Hogg-Johnson SA: Measuring health in injured workers: a cross-sectional comparison of five generic health status instruments in workers with musculoskeletal injuries. Am J Ind Med 1996, 29:618-631.

26. Kleinman WB, Bishop AT: Anterior intramuscular transposition of the ulnar nerve. J Hand Surg Am 1989, 14:972-979.

27. Cieza A, Geyh S, Chatterji S, Kostanjsek N, Ustun B, Stucki G: ICF linking rules: an update based on lessons learned. J Rehabil Med 2005, 37:212-218

28. Cieza A, Stucki G: Content comparison of health-related quality of life (HRQOL) instruments based on the international classification of functioning, disability and health (ICF). Qual Life Res 2005, 14:1225-1237.

29. Shrout PE, Fleiss JL: Intraclass correlations: uses in assessing rater reliability. Psychol Bull 1979, 86:420-428.

30. Turner D, Schunemann HJ, Griffith LE, Beaton DE, Griffiths AM, Critch JN, et al: The minimal detectable change cannot reliably replace the minimal important difference. J Clin Epidemiol 2010, 63:28-36.

31. Stratford PW, Riddle DL: When minimal detectable change exceeds a diagnostic test-based threshold change value for an outcome measure: resolving the conflict. Phys Ther 2012, 92:1338-1347.

32. Joliffe IT, Morgan BJ: Principal component analysis and exploratory factor analysis. Stat Methods Med Res 1992, 1:69-95.

33. Zimmerman NB, Kaye MB, Wilgis EF, Zimmerman RM, Dubin NH: Are standardized patient self-reporting instruments applicable to the evaluation of ulnar neuropathy at the elbow? J Shoulder Elbow Surg 2009, 18:463-468.

34. Kose G, Hepguler S, Atamaz F, Oder G: A comparison of four disability scales for Turkish patients with neck pain. J Rehabil Med 2007, 39:358-362.

35. Beaton DE, Bombardier C, Katz JN, Wright JG: A taxonomy for responsiveness. J Clin Epidemiol 2001, 54:1204-1217.

36. Cibelli K: Cognitive Interviewing Techniques: A Brief Overview. http://www. docstoc.com/docs/98959508/Cognitive-Interviewing-Techniques.

37. Ojanen J, Gogates G: A briefing on cognitive debriefing. Good Clin Pract J 2006, 13:1-29.

38. Gelberman RH, Szabo RM, Williamson RV, Dimick MP: Sensibility testing in peripheral-nerve compression syndromes. An experimental study in humans. J Bone Joint Surg Am 1983, 65:632-638.

39. The Patient-Reported Outcomes Measurement Grou. Instrument Selection. The National Centre for Health Outcomes Development, Oxford University; 2008. http://phi.uhce.ox.ac.uk/inst_selcrit.php.

40. Fleiss JL: Reliability of Measurement. In The Design and Analysis of Clinical Experiments. Edited by Fleiss JL. Toronto: John Wiley and Son; 1986:1-32.

\section{doi:10.1186/1471-2474-14-146}

Cite this article as: MacDermid and Grewal: Development and validation of the patient-rated ulnar nerve evaluation. BMC Musculoskeletal Disorders 2013 14:146.

\section{Submit your next manuscript to BioMed Central and take full advantage of:}

- Convenient online submission

- Thorough peer review

- No space constraints or color figure charges

- Immediate publication on acceptance

- Inclusion in PubMed, CAS, Scopus and Google Scholar

- Research which is freely available for redistribution 